\title{
Metformin associated lactic acidosis: a case series of 28 patients treated with sustained low-efficiency dialysis (SLED) and long-term follow-up
}

Andrea Angioi ${ }^{1 \dagger}$, Gianfranca Cabiddu ${ }^{1}$, Maura Conti ${ }^{1}$, Gianfranco Pili ${ }^{1}$, Alice Atzeni ${ }^{1}$, Valeria Matta ${ }^{1}$, Riccardo Cao ${ }^{1}$, Matteo Floris ${ }^{1}$, Marco Songini ${ }^{2}$, Maria Franca Mulas², Mitchell Rosner ${ }^{3}$ and Antonello Pani ${ }^{1 *+}$ (D)

\begin{abstract}
Background: Metformin associated lactic acidosis (MALA) is a well-known serious side effect of biguanides. However, the best treatment strategy remains a matter of debate. In the last 14 years, we observed a significant increase in hospitalizations for MALA to our Center. We report the outcomes of our clinical and therapeutic approach.

Methods: This is a single-center case series. Twenty-eight patients affected with MALA and acute kidney failure admitted between January 2000 and September 2014 were included. We analyzed comorbidities, laboratory tests and clinical parameters at admission, at $36 \mathrm{~h}$ and at discharge. All patients were treated with sustained low-efficiency dialysis (SLED) until normalization of serum lactate ( $\leq 3 \mathrm{mmol} / \mathrm{L}$ ), bicarbonate (between 20 and $25 \mathrm{mmol} / \mathrm{L}$ ) and potassium (between 4.0 and $5.1 \mathrm{mmol} / \mathrm{L}$ ).

Results: The mortality rate was $21.4 \%$, with all of the events occurring within $24 \mathrm{~h}$ from admission, and before or during the first hemodialysis treatment. Precipitating causes included; acute dehydration (86.4\%), systemic inflammatory response syndrome (SIRS) (57.1\%), sepsis (10.7\%), nephrolithiasis (14.6\%) and exposure to iodinated contrast (7.1\%). No further episodes of lactic acidosis were described after discontinuing the drug over a mean follow-up of 27.2 months. Furthermore, while in 2010, we had a peak incidence of MALA of 76.8 cases per 100,000 patients on metformin, this rate fell after an education campaign conducted by specialists on the proper usage of metformin in patients at risk of MALA. Although the fall in incidence after the educational program was not necessarily causal, in 2014 the incidence was $32.9 / 100,000$.

Conclusions: We report an improved mortality rate in patients affected with MALA and acute kidney injury treated with SLED compared with other series published in literature. Rapid introduction of effective hemodialysis is critical in improving outcomes.
\end{abstract}

Keywords: Lactic acidosis, Metformin, Acute kidney injury, SLED, Hemodialysis

\footnotetext{
* Correspondence: antonellopani@aob.it

${ }^{\dagger}$ Equal contributors

'Division of Nephrology and Dialysis, Azienda Ospedaliera G. Brotzu, Piazzale

Ricchi n¹, 09134 Cagliari, Italy

Full list of author information is available at the end of the article
} 


\section{Background}

Metformin is a first line drug therapy both to treat type 2 diabetes mellitus as well as prevent diabetic-related complications [1-3]. It is widely considered safe and well tolerated. Mechanistically, metformin counters insulin resistance by enhancing the basal cellular uptake of glucose, and by blocking the precursors of gluconeogenesis in the liver. Clinical research demonstrated that metformin reduces postprandial glycemia by $20-30 \%$ and, as demonstrated in the United Kingdom Prospective Diabetes Study (UKPDS 34), can delay the onset of micro and macrovascular disease [2, 4-6]. Moreover, it reduces all-cause mortality $(-36 \%)$, as well as diabetes-related complications (32\%) and diabetes-related deaths (-47\%) [7]. In addition, a number of pleiotropic effects have been reported such as improvement of non-alcoholic steatohepatitis [8].

Despite these benefits, some at risk populations, in particular patients with renal disease and low glomerular filtration rates (GFR) $(\leq 60 \mathrm{ml} / \mathrm{min})$ can accumulate metformin in tissues leading to lactic acidosis, which can be life threating [9]. This phenomenon is explained through in vitro and in vivo observations: metformin reduces oxidative phosphorylation, increasing serum lactate levels if drug concentrations rise excessively $[10,11]$. The magnitude of metformin associated lactic acidosis (MALA) is matter of debate; in controlled studies, it is diagnosed in 4.3 per 100,000 patient-years [12]. However, several case series described a much higher incidence that likely is more reflective of the "real world" situation [13]. Metformin associated lactic acidosis (MALA) is defined as a lactic acidosis in a patient with documented regular intake of metformin as well as comorbid conditions that increase the risk of lactic acidosis such as heart failure and kidney disease [14].

Over the last fourteen years we had observed a considerable annual incidence of MALA in the setting of acute kidney injury (AKI) or acute on chronic kidney disease (AoCKD) at our Center. MALA often occurred in patients with an exacerbation of comorbid conditions. In order to better understand the etiology and outcomes of MALA, we reviewed a case series of patients who were admitted to our Center with a diagnosis of MALA and AKI. The main aim of our analysis was to evaluate the efficacy of our clinical and therapeutic approach as compared with the reported outcomes in the literature in terms of overall survival in the short (7 days) and long term (last follow-up or phone interview).

\section{Methods}

This is a retrospective, single center, case series of MALA and AKI. The Division of Nephrology and Dialysis of the Azienda Ospedaliera G. Brotzu, Cagliari, Italy, cared for all cases. Patients included in the analysis: type 2 diabetes mellitus diagnosed at least one year earlier; metformin use as monotherapy or concomitant with other anti-diabetic medications before the development of lactic acidosis; acute kidney failure (AKI stage III) according with KDIGO Clinical Practice Guideline for Acute Kidney Injury [15]; metabolic acidosis as defined by the reduction of serum $\mathrm{pH}$ $(\leq 7.34$ [7:35-7.42]) and serum bicarbonate $(\leq 22 \mathrm{mmol} / \mathrm{L}$ [22-26]); and lactic acidosis (metabolic acidosis with an increased anion gap and lactate concentration $\geq 5 \mathrm{mmol} / \mathrm{L}$ ). Those patients not meeting the above listed criteria were excluded from analysis.

We identified 28 patients with a diagnosis of MALA and AKI who were admitted to our Division between January 2000 and September 2014 (Table 1). Protocol. Metformin was discontinued in the identified patients and treatment for diabetes was initiated with insulin and/or a low carbohydrate diet. In all cases, patients were treated with a sustained low-efficiency dialysis (SLED) using bicarbonate buffer. The goal of the treatment was metabolic normalization, in particular lactate ( $\leq 3 \mathrm{mmol} / \mathrm{L}$ ), bicarbonate (between 20 and $25 \mathrm{mmol} / \mathrm{L}$ ) and potassium (between 4.0 and $5.1 \mathrm{mmol} / \mathrm{L}$ ). A metabolic panel was requested every $2 \mathrm{~h}$ during the treatment to prevent overcorrections and ensure that goals were being met, and every $12 \mathrm{~h}$ after the treatment. Of note, severe hyperkalemia was gradually corrected to ensure hemodynamic stability and avoid sudden drops of the serum concentration of potassium. In particular, if serum potassium was high $(\geq 6.5 \mathrm{meq} / \mathrm{l})$, we first corrected it with a potassium concentration of 5 in the bath and then subsequently lowered the potassium with less concentrated solutions.

Patients did not receive sodium bicarbonate i.v. before hemodialysis. Since there is little correlation between serum metformin drug levels with outcomes, metformin levels were not measured. Vital signs and laboratory studies were recorded at admission, three days after admission, and at discharge.

\section{Follow-up}

After discharge, most of the 23 surviving patients were followed at our outpatient clinic. After a mean of $27.2 \pm$ 24.8 months from metformin discontinuation, we asked survivors whether they experienced similar episodes in the future, about their knowledge on the drug side effects before the event and if they resumed the intake of the drug after the event.

\section{Educational campaign}

In 2010 we observed the peak of a progressive annual rise in the incidence of MALA. This triggered us to organize several dedicated courses on MALA for specialists and general practitioners, and specific sessions in 
Table 1 Descriptive statistics of selected patients at admission. M:F (male/female ratio); SD (standard deviation); CKD (chronic kidney disease)

\begin{tabular}{|c|c|}
\hline \multicolumn{2}{|l|}{ Demographics and baseline characteristics } \\
\hline \multicolumn{2}{|l|}{ Demographics } \\
\hline $\mathrm{N}^{\circ}$ of patients & 28 \\
\hline$M: F$ & 1.5: 1 \\
\hline Mean age \pm SD & $66.7 \pm 9$ \\
\hline$\%$ of $\geq 65$ years & 60.7 \\
\hline$\%$ of $\geq 80$ years & 3.5 \\
\hline \multicolumn{2}{|l|}{ Status on admission } \\
\hline $\begin{array}{l}N^{\circ} \text { days with symptoms } \pm \text { SD before } \\
\text { the admission }\end{array}$ & $6.04 \pm 5$ \\
\hline Days of admission & $10.6 \pm 6.7$ \\
\hline Systolic Pressure (mmHg) & $125 \pm 32.3$ \\
\hline Diastolic Pressure (mmHg) & $64.6 \pm 16$ \\
\hline Body temperature $\left({ }^{\circ} \mathrm{C}\right)$ & $36.9 \pm 0.8$ \\
\hline$\%$ Oliguria & 71.4 \\
\hline \multicolumn{2}{|l|}{ Renal function } \\
\hline Mean $\mathrm{s} C r(\mathrm{mg} / \mathrm{dl})$ before the admission & $1.16 \pm 0.48$ \\
\hline $\begin{array}{l}\text { Mean eGFR CKD EPI (ml/min/1.73 m2) before } \\
\text { the admission }\end{array}$ & $71.9 \pm 26.5$ \\
\hline AKI stage (\%) & $\begin{array}{l}\text { Stage I - 0\% } \\
\text { Stage II - 3.6\% } \\
\text { Stage III - } 96.4\end{array}$ \\
\hline CKD stage $\mathrm{n}(\%)$ before the $\mathrm{AKI}$ & $\begin{array}{l}\text { Stage I - } 14(50) \\
\text { Stage II - } 7(25) \\
\text { Stage III - } 7(25) \\
\text { Stage IV - } 0(0) \\
\text { Stage V - } 0(0)\end{array}$ \\
\hline \multicolumn{2}{|l|}{ Comorbidities } \\
\hline$\%$ Heart Failure & 14.2 \\
\hline$\%$ lodinated contrast agent & 3.5 \\
\hline$\%$ Moderate to severe anemia & 35.7 \\
\hline$\%$ Vascular disease & 21.4 \\
\hline$\%$ Non-acute pulmonary disease & 7.1 \\
\hline$\%$ SIRS & 57.1 \\
\hline \% Sepsis & 14.2 \\
\hline \multicolumn{2}{|l|}{ Treatment } \\
\hline$\%$ Hemodialysis post-admission & 100 \\
\hline Number of hemodialysis sessions & $2.26 \pm 2$ \\
\hline
\end{tabular}

local congresses held by diabetologists, internists and nephrologists.

Laboratory parameters are expressed as mean and standard deviation (SD) for normally distributed variables and median and interquartile range for non-parametric data. The evolution of lab exams at admission and after 3 days was reported and differences were assessed with the paired t-test. Statistical analysis was carried out using SPSS 22 (IBM Corporation, USA).
We defined systemic inflammatory response syndrome (SIRS) and sepsis as recommended by ACCP/SCCM (2012) [16].

\section{Results}

We identified 28 patients diagnosed with MALA from our hospital records. There was a prevalence of males (M:F 1.5:1), and the mean age was $66.7 \pm 9.5 \mathrm{yrs}$. Clinical and laboratory findings at admission were diagnostic for AKI stage 2 in 3.6\% and stage 3 in $96.4 \%$ of patients (Table 1). However, after the first $24 \mathrm{~h}$ of observation, all patients met criteria for AKI stage III. Notably, $50 \%$ of MALA cases were observed in subjects with previously normal kidney function, and in 25\% of cases, MALA developed in subjects with previously diagnosed mild to moderate chronic kidney disease $(\mathrm{sCr} 1.16 \pm 0.48 \mathrm{mg} / \mathrm{dl}$; eGFR CKD-EPI $71.9 \pm 26.5 \mathrm{ml} / \mathrm{min} / 1.73 \mathrm{~m} 2$ ) (Table 2). Comorbid conditions included: hypertension (71.4\%), neoplastic disease (17.9\%), chronic obstructive pulmonary disease (COPD) (7.1\%) and heart failure (14.3\%) (Additional file 1: Table S1). We did not identify any combination of comorbidities associated with an increased risk for mortality. Our cohort was treated as follows: a mean of $6.9 \pm 1.8 \mathrm{~h}$ of treatment were provided with low blood fluxes (QB from 80 to $140 \mathrm{ml} / \mathrm{min}$ ) due to cardiovascular instability and mono-lumen catheters that we use for an urgent dialysis; dialyzers were based on multi-branded polysulfone membranes.

A limited number of causes in this patient cohort that could worsen kidney function were identified. These included pre-renal etiologies, volume depletion (85.7\%) secondary to nausea and vomiting $(53.6 \%$ and $57.1 \%$,

Table $\mathbf{2}$ Laboratory parameters at time 0 (admission) and at $36 \mathrm{~h}$, intended as means and standard deviation (SD); EB (excess of bases), $\mathrm{pCO}_{2}\left(\mathrm{CO}_{2}\right.$ partial blood pressure)

Laboratory parameters at time 0 (admission) and at $36 \mathrm{~h}$, intended as means and standard deviation (SD)

\begin{tabular}{|c|c|c|c|}
\hline Variable (mean $\pm \mathrm{SD})$ & Time 0 & Time 1 (36 h) & Sig. \\
\hline Serum Creatinine (mg/dl) & $8.1 \pm 3.1$ & $5.3 \pm 2.8$ & $p<0.05$ \\
\hline Blood Urea Nitrogen (mg/dl) & $96.8 \pm 47.4$ & $54.6 \pm 27.4$ & $p<0.05$ \\
\hline Hemoglobin (g/dl) & $10.7 \pm 1.6$ & $11.2 \pm 1.8$ & $p N S$ \\
\hline Potassium (mEq/L) & $5.93 \pm 1.4$ & $4.03 \pm 0.8$ & $p<0.05$ \\
\hline Glycemia (mg/dl) & $178.8 \pm 123$ & $160.1 \pm 24$ & $p N S$ \\
\hline C-reactive protein (mg/dl) & $8.6 \pm 8.9$ & $4.3 \pm 2.3$ & $p<0.05$ \\
\hline $\mathrm{pH}$, serum & $7.01 \pm 0.22$ & $7.35 \pm 0.7$ & $p<0.05$ \\
\hline $\mathrm{HCO}_{3}-(\mathrm{mmol} / \mathrm{L})$ & $7.72 \pm 4.4$ & $22.7 \pm 6.4$ & $p<0.05$ \\
\hline $\mathrm{EB}(\mathrm{mmol} / \mathrm{L})$ & $-19.3 \pm 11.7$ & $-1.92 \pm 5.6$ & $p<0.05$ \\
\hline Lactate $(\mathrm{mmol} / \mathrm{L})$ & $13.7 \pm 6$ & $2.6 \pm 2.6$ & $p<0.05$ \\
\hline Anion gap (mmol/L) & $36.2 \pm 8.2$ & $13.2 \pm 4.1$ & $p<0.05$ \\
\hline $\mathrm{VpCO}_{2}(\mathrm{mEq} / \mathrm{L})$ & $25.7 \pm 9.5$ & $39.1 \pm 4.4$ & $p<0.05$ \\
\hline $\mathrm{VpO}_{2}(\mathrm{mEq} / \mathrm{L})$ & $65.4 \pm 10.5$ & $42.4 \pm 9.9$ & $p<0.05$ \\
\hline
\end{tabular}


respectively). Nephrolithiasis caused post-renal acute renal failure in $14.3 \%$ of patients. Systemic inflammatory response syndrome (SIRS) was frequently diagnosed (57.1\%), and $10.7 \%$ of hospitalized patients had criteria diagnostic of sepsis (E. coli was the most frequent pathogen $(2 / 4$ cases $))$. Two patients developed AKI after administration of iodinated contrast medium, developing MALA because metformin had not been discontinued. Mild (10-12 g/dl) to moderate (8-9.9 g/dl) anemia often concurred in this condition (37.5\%).

Elevated levels of serum creatinine (mean: $8.1 \pm 3.1 \mathrm{mg} / \mathrm{dL}$ ) and blood urea nitrogen (mean: $96.8 \pm 47.4 \mathrm{mg} / \mathrm{dL}$ ), as well as hyperkalemia (mean: $5.93 \pm 1.4 \mathrm{mEq} / \mathrm{L}$ ), low $\mathrm{pH}$ values (median: $7.01 \pm 0.22$ ) and elevated blood lactate values (median: $13.7 \pm 6 \mathrm{mEq} / \mathrm{L}$ ) characterized patients at admission. After their first emergency hemodialysis, 21.4\% of patients died. This occurred within the first $24 \mathrm{~h}$ of admission (Fig. 1). Mean hospitalization length was $10.6 \pm 6.7$ days, and a mean of only $2.26 \pm 2$ hemodialytic sessions (HD) were performed. Kidney function rapidly recovered in the surviving patients, and in some cases within $36 \mathrm{~h}$. Metabolic parameters also normalized significantly within the same time frame $(\mathrm{pH}[7.36 \pm 0.072], \mathrm{HCO} 3-$ $[22.71 \pm 6.44 \mathrm{mmol} / \mathrm{L}]$, lactate levels $[2.6 \pm 2.65 \mathrm{mmol} / \mathrm{L}]$ ). Patients who were oliguric at admission recovered urine output within 36 h. At discharge, metabolic parameters were still within normal range, but $14.8 \%$ of patients did not recover to their previous values of renal function. We did not observe any MILA, unlike occasionally reported in the literature $[17,18]$.
These subjects were then followed-up as outpatients for a mean of 27.2 months in order to assess changes in kidney function and to document whether lactic acidosis reappeared despite metformin discontinuation. Telephone interviews allowed us to collect data from the other patients cared for in other facilities. A brief interview with the patients and their relatives revealed that: 1) none of them knew how to recognize either the initial symptoms of MALA or the signs and risks of sudden decline in kidney function. Above all, none of the patients knew when to discontinue metformin if they developed an illness and therefore they all continued taking the drug until admission to hospital; 2) after discharge, 2 of 23 patients died from causes other than lactic acidosis; 3) no new episodes of lactic acidosis were reported; 4) the onset of symptoms that led to a diagnosis of MALA started a mean of 6 days before admission.

Considering that our operative area accounts for 552.303 inhabitants and that 1.55 individuals out of every 100 have a prescription for metformin, we estimated that in our district there are about 8560 patients taking metformin. Thus, in 2010, we had a peak incidence of MALA of 76.8 cases per 100,000 patients on metformin, that fell after an education campaign conducted by specialists on its usage in patients at risk of MALA (Additional file 2: Figure S1). Although the fall in incidence after the educational program is not necessarily causal, in 2014 the incidence was 32.9/100,000, while prescription rate remained almost stable in this period.

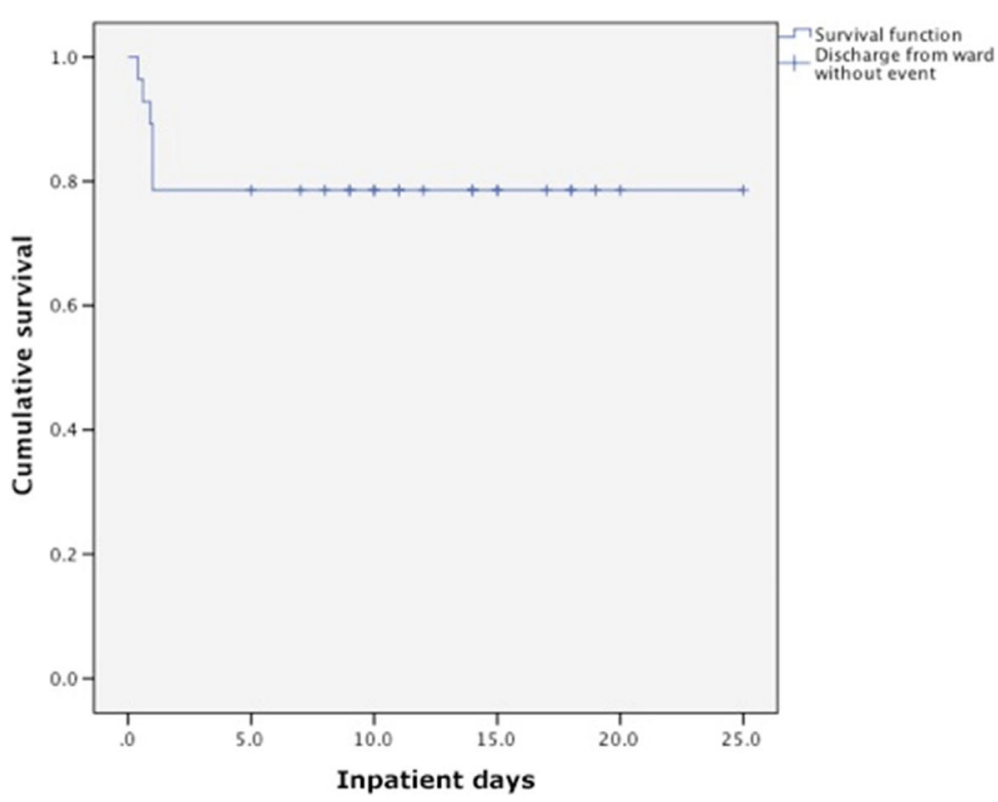

Fig. 1 Kaplan-Meier survival curve of admitted-discharged patients affected with MALA (admission, time 0 - 25 days). Discharged patients are marked as censored. During the follow-up (mean 27.2 months), none of the surviving patients experienced new episodes of lactic acidosis after discontinuing the drug. Two patients died at follow-up for reasons other than lactic acidosis 


\section{Discussion}

Currently, type 2 diabetes is progressing at alarming rates in Europe, US and Italy [19,20]. Although there are no official data regarding the incidence of T2D in Sardinia, some regional reports show a growing tendency, estimated at about 5000 new cases every year. The number of affected subjects is estimated around 94,000 [20]. In Italy, antidiabetic drug use increased by $37 \%$ between 2000 and 2009 [3], especially oral antidiabetics $(+22 \%)$. Prescriptions for metformin as the initial treatment for incident cases of type 2 diabetes increased exponentially, going from $8.3 \%$ in 1998 to $54.3 \%$ in 2010 [21]. The result of an increase in the number of prescriptions is, of course, an increase in the number of reported adverse events [22]. The most serious side effect of metformin is lactic acidosis, a form of severe metabolic acidosis with a concomitant increase in serum concentrations of lactate $\geq 5 \mathrm{mmol} / \mathrm{L}$. This is the result of blockade of pyruvate flow through its metabolic pathway induced by high levels of metformin. Pyruvate is the product of glucose metabolism through glycolysis and subsequently enters into the mitochondrial Krebs Cycle and oxidative phosphorylation. This blockade leads to a significant decrease in ATP generation and an increase in protons, resulting in a consequent reduction of $\mathrm{pH}$ in the cytoplasmic fluid due to continuous ATP hydrolysis [21]. This ultimately leads to a block in pyruvate metabolism and the excess pyruvate that cannot be managed by the mitochondria is transformed into lactate, especially within the liver, intestine and, to a lesser extent, in other tissues [23, 24]. It is well known that MALA often occurs as the consequence of an abrupt increase in the concentration of metformin in tissues and serum, often following a rapid decline in kidney function and decrease in metformin excretion [25].

Although rare, MALA generated a great deal of concern that delayed the introduction of metformin into the US market until May, 1995 [26]. This was only after extended studies and meta-analyses determined that the condition was rare especially in those with normal kidney function [22, 27]. A Cochrane meta-analysis carried out by Salpeter et al. included reports published between January, 1959 and October, 2009, and involved 70,490 patients who had taken metformin for at least 1 month [12]. The results showed an annual MALA incidence of 4.3 cases per 100,000 patient-years in the metformin group and 5.4 per 100,000 patient-years in the non-metformin group, resulting in a paradoxical protective effect of metformin against lactic acidosis due to other causes. However, the work by Salpeter actually estimated the incidence of MILA, a lactic acidosis generated by a metformin poisoning alone and known to be quite uncommon, instead of MALA. In fact, it differs significantly from the "real world" experience, where several comorbidities able to generate lactic acidosis may easily coexist in our patients.

Of note, many cases of MALA may have been prevented before "the point of no return" by discontinuing the drug at the onset of suspicious symptoms or when patients developed conditions such as volume depletion which would reduce GFR and increase metformin levels. So far in 2014, the incidence of the phenomenon is half what it was in 2010, but still high, as reported in other recent papers [28]. Moreover, the National Pharmacovigilance Network, a system for data collection and management of suspected adverse reactions of the Italian Medicines Agency, analyzed the cases of MALA reported only 59 new cases of MALA in the 10 year period November 2001 to October 2011, suggesting elevate rates of missed reports [29].

Our patients were affected by comorbidities that may themselves generate lactic acidosis independently of metformin use. However, arguing against this is that after discontinuing the drug, there were no further events. In fact, MALA is currently the main etiology of lactic acidosis among the patients in our ward. Mortality was relatively low in our cohort $(21.4 \%)$ and all deaths occurred within $24 \mathrm{~h}$ of admission. A review of electrocardiographic data in these deaths revealed ventricular tachycardia first, then followed by ventricular fibrillation. The 24-h critical limit for mortality has also been reported by other authors in the literature [27]. Mortality was below $45 \%$ in a meta-analysis by Lalau et al., but higher compared to our data [30]. Another report from Seidowsky et al showed even a higher mortality incidence of $48 \%$ [31].

The death events occurred during the first hemodialytic treatment (after a mean of $3: 15 \mathrm{~h}$ of treatment, around $5 \mathrm{~h}$ since admission) or soon after (two patients died $24 \mathrm{~h}$ since admission and one patient after $22 \mathrm{~h}$ ). Patients had very similar clinical presentations, commonly with moderate to severe dehydration associated with vomiting, diarrhea and oliguria. Upon admission to our Division, blood gases often showed high levels of venous $\mathrm{pO} 2$, most likely because of hyperventilation secondary to severe acidosis and the exclusion of the Krebs cycle from cellular metabolism due to metformin intoxication, in agreement with Protti et al [32].

We believe that the improved mortality seen in our cohort is due to aggressive use of SLED along with more gradual correction of metabolic derangements. Interestingly, recent guidelines had been published by the EXTRIP workgroup, that are much more conservative compared with our approach. In fact, hemodialysis is indicated if any of the following conditions (lactate concentration greater than $20 \mathrm{mmol} / \mathrm{L} ; \mathrm{pH}$ less than or equal to 7.0; shock; Failure of standard supportive measures; decreased level of consciousness) were present. 
Instead, we preferred to be more aggressive with the use of dialysis, prescribing SLED in every patient taking metformin with lactic acidosis (metabolic acidosis with an increased anion gap and lactate concentration $\geq 5 \mathrm{mmol} / \mathrm{L}$ ) and AKI stage III.

The renal replacement therapy utilized in our protocol was based on a bicarbonate buffer and intermittent SLED to ensure adequate clearance of metformin. After the first SLED and volume correction, a second session was often needed (mean: $2.26 \pm 2$ treatments) to achieve lactate $\leq 5 \mathrm{mmol} / \mathrm{L}$. This is in agreement with the kinetics of the drug, resulting in complete removal in about $48 \mathrm{~h}$ [33]. Very slow correction of potassium was critical to avoid polarization abnormalities in conduction tissues, especially in subjects whose $\mathrm{K}^{+} \geq 7 \mathrm{mEq} / \mathrm{L}$. The use of these strategies led to an improvement in renal function within 3 days of admission, thus allowing patients to be weaned from replacement therapy. Prolonged hospitalization (mean: 10.6 \pm 6.7 days) was often necessary to complete the diagnostic and therapeutic plan and to stabilize all clinical parameters, including control of glycemia with the new insulin regimens. Unfortunately, $14.8 \%$ of patients did not regain their previous eGFR values. No other deaths due to lactic acidosis were reported a mean of 27.2 months after discontinuing metformin, and no new episodes of lactic acidosis were observed. This is an indirect sign of the key role of metformin in the genesis of MALA.

Our study has several limitations. First, given the small number of patients in our study, we did not find any correlation between death and clinical or laboratory variables. Theoretically, comorbidities could influence this outcome, but neither respiratory, cardiac, nor renal disease had a clear impact on outcome in this case series. This suggests that MALA may be fatal independently from comorbidities. Overall, there is very little information available to predict the evolution of this condition [21]. Second, we did not provide any control group to demonstrate a significant improvement of survival in MALA compared to other conditions characterized by lactic acidosis.

\section{Conclusions}

In conclusion, we report a high incidence (in 2014, 32.9/ 100,000 patient) but a relatively low mortality rate (21.4\%) of MALA. MALA tended to be precipited by AKI mainly due to volume depletion. Importantly, patients had little insight into how to manage their metformin dosing as they continued their daily intake of the drug until toxic levels were reached despite having conditions that increased risk such as nausea and vomiting. SLED hemodialysis and a very slow correction of the metabolic profile was effective and led to satisfactory outcomes in patients with MALA.

\section{Additional files}

Additional file 1: Table S1. Comorbidities and precipitating factors associated with lactic acidosis (MALA). Death events are marked red. (PPTX 47 kb)

Additional file 2: Figure S1. Incidence of MALA observed to our Division between January 2000 and September 2014. It is indicated the extensive educational campaign done by our Division for internal medicine and metabolism specialists. (PPTX 105 kb)

\begin{abstract}
Abbreviations
AKI: Acute kidney injury; AoCKD: Acute on chronic kidney disease; COPD: Chronic obstructive pulmonary disease; eGFR: Estimated glomerular filtration rate; HD: Hemodialysis; KDIGO: Kidney Disease: Improving Global Outcomes; MALA: Metformin associated lactic acidosis; MILA: Metformin induced lactic acidosis; SIRS: Systemic inflammatory response syndrome; SLED: Sustained low efficiency dialysis; T2D: Type 2 diabetes
\end{abstract}

Acknowledgements

Not applicable.

\section{Funding}

We did not receive any funding to support the design of the study and collection, analysis, and interpretation of data and in writing the manuscript.

Availability of data and materials

The datasets generated during and/or analyzed during the current study are not publicly available due to the inclusion of sensitive privacy data, but are available from the corresponding author on reasonable request.

\section{Authors' contributions}

AP and AA1 researched data, contributed to discussion, wrote the manuscript, and reviewed and edited the manuscript. MR contributed to discussion, wrote the manuscript, reviewed and edited the manuscript. MS, MF, MFM contributed to discussion, and reviewed and edited the manuscript. MC, GP, AA2, VM, PM, RC, GC reviewed and edited the manuscript. AP and AA1 are the guarantor of this work and had full access to all the data in the study and takes responsibility for the integrity of the data and the accuracy of the data analysis. All authors read and approved the final manuscript.

\section{Ethics approval and consent to participate}

The current study has been approved by the ethics committee of Azienda Ospedaliera G. Brotzu; at the admission, we asked for a written consent to every patient (or their relatives when patients were not able to give a consent). This retrospective research involved human subjects and human data. The dataset has been built in an anonymous way by direct care physicians. Only direct care physicians had the access to this database. No other third persons were allowed to consult this database, although totally anonymized. This study has been performed in accordance with the Declaration of Helsinki.

Consent for publication Not applicable.

\section{Competing interests}

The authors declare that they have no competing interests. Dr. Antonello Pani is a member of the editorial board (Associate Editor) of this Journal.

\section{Publisher's Note}

Springer Nature remains neutral with regard to jurisdictional claims in published maps and institutional affiliations.

\section{Author details}

'Division of Nephrology and Dialysis, Azienda Ospedaliera G. Brotzu, Piazzale Ricchi n¹, 09134 Cagliari, Italy. ${ }^{2}$ Diabetology Unit, Azienda Ospedaliera G. Brotzu, Cagliari, Italy. ${ }^{3}$ Division of Nephrology, University of Virginia Health System, Charlottesville, Virginia, USA. 
Received: 13 April 2017 Accepted: 15 March 2018 Published online: 02 April 2018

\section{References}

1. Grant RW, Kirkman MS. Trends in the Evidence Level for the American Diabetes Association's "Standards of Medical Care in Diabetes" From 2005 to 2014. Diabetes Care. 2015;38(1):6-8

2. Effect of intensive blood-glucose control with metformin on complications in overweight patients with type 2 diabetes (UKPDS 34). UK Prospective Diabetes Study (UKPDS) Group. Lancet. 1998;352(9131):854-65.

3. Associazione Medici Diabetologi. Standard italiani per la cura del diabete mellito 2014 wwwstandarditalianiit 2014.

4. DeFronzo RA, Goodman AM. Efficacy of metformin in patients with non-insulin-dependent diabetes mellitus. The Multicenter Metformin Study Group. N Engl J Med. 1995;333(9):541-9.

5. National Institute of Diabetes and Digestive and Kidney Diseases. Diabetes statistics. Bethesda (MD): US Department of Health and Human Services. NIH publication 2014(Report no.: 94-3822).

6. Walters DP, Gatling W, Mullee MA, Hill RD. The distribution and severity of diabetic foot disease: a community study with comparison to a nondiabetic group. Diabet. Med. J. British Diabetic Assoc. 1992;9(4):354-8.

7. Bannister CA, Holden SE, Jenkins-Jones S, Morgan CL, Halcox JP, Schernthaner G, Mukherjee J, Currie CJ. Can people with type 2 diabetes live longer than those without? A comparison of mortality in people initiated with metformin or sulphonylurea monotherapy and matched, non-diabetic controls. Diabetes Obes Metab. 2014;16(11):1165-73.

8. Scarpello $\mathrm{JH}$, Howlett HC. Metformin therapy and clinical uses. Diab. Vasc. Dis. Res : Off J Int Soc Diab. Vasc. Dis. Res. 2008;5(3):157-67.

9. Evans JM, Ogston SA, Emslie-Smith A, Morris AD. Risk of mortality and adverse cardiovascular outcomes in type 2 diabetes: a comparison of patients treated with sulfonylureas and metformin. Diabetologia. 2006:49(5):930-6.

10. Madiraju AK, Erion DM, Rahimi $Y$, Zhang XM, Braddock DT, Albright RA, Prigaro BJ, Wood JL, Bhanot S, MacDonald MJ, et al. Metformin suppresses gluconeogenesis by inhibiting mitochondrial glycerophosphate dehydrogenase. Nature. 2014;510(7506):542-6.

11. Brown JB, Conner C, Nichols GA. Secondary failure of metformin monotherapy in clinical practice. Diabetes Care. 2010;33(3):501-6.

12. Salpeter SR, Greyber E, Pasternak GA, Salpeter Posthumous EE. Risk of fatal and nonfatal lactic acidosis with metformin use in type 2 diabetes mellitus. Cochrane Database Syst. Rev. 2010;1:CD002967.

13. Brown JB, Pedula K, Barzilay J, Herson MK, Latare P. Lactic acidosis rates in type 2 diabetes. Diabetes Care. 1998:21(10):1659-63.

14. Lalau JD, Race JM. Lactic acidosis in metformin therapy: searching for a link with metformin in reports of 'metformin-associated lactic acidosis'. Diabetes Obes Metab. 2001;3(3):195-201.

15. KDIGO: Clinical Practice Guideline for Acute Kidney Injury 2012.

16. Bone RC, Balk RA, Cerra FB, Dellinger RP, Fein AM, Knaus WA, Schein RM, Sibbald WJ. Definitions for sepsis and organ failure and guidelines for the use of innovative therapies in sepsis. The ACCP/SCCM Consensus Conference Committee. American College of Chest Physicians/Society of Critical Care Medicine. Chest. 1992;101(6):1644-55.

17. Heaney D, Majid A, Junor B. Bicarbonate haemodialysis as a treatment of metformin overdose. Nephrol. Dial. Transplant. : official Dial. Transplant Assoc. Eur. Ren. Assoc. 1997;12(5):1046-7.

18. Panzer U, Kluge S, Kreymann G, Wolf G. Combination of intermittent haemodialysis and high-volume continuous haemofiltration for the treatment of severe metformin-induced lactic acidosis. Nephrol. Dial. Transplant. : Off pub Dial. Transplant Assoc. Eur. Ren. 2004;19(8):2157-8.

19. Cowie CC, Rust KF, Byrd-Holt DD, Eberhardt MS, Flegal KM, Engelgau MM, Saydah SH, Williams DE, Geiss LS, Gregg EW. Prevalence of diabetes and impaired fasting glucose in adults in the U.S. population: National Health And Nutrition Examination Survey 1999-2002. Diabetes Care. 2006;29(6):1263-8.

20. International Diabetes Federation. Diabetes: facts and figures. 2007 (http://www.who.int/diabetes/en/). Accessed Mar 2018.

21. Lalau JD, Arnouts P, Sharif A, De Broe ME. Metformin and other antidiabetic agents in renal failure patients. Kidney Int. 2015;87(2):308-22.

22. van Berlo-van de Laar IR, Vermeij CG, Doorenbos CJ. Metformin associated lactic acidosis: incidence and clinical correlation with metformin serum concentration measurements. J Clin Pharm Ther. 2011;36(3):376-82.
23. Wang DS, Kusuhara H, Kato $Y$, Jonker JW, Schinkel AH, Sugiyama $Y$. Involvement of organic cation transporter 1 in the lactic acidosis caused by metformin. Mol Pharmacol. 2003;63(4):844-8.

24. Dykens JA, Jamieson J, Marroquin L, Nadanaciva S, Billis PA, Will Y. Biguanide-induced mitochondrial dysfunction yields increased lactate production and cytotoxicity of aerobically-poised HepG2 cells and human hepatocytes in vitro. Toxicol Appl Pharmacol. 2008;233(2):203-10.

25. Bailey CJ, Turner RC. Metformin. N Engl J Med. 1996;334(9):574-9.

26. Williams RH, Palmer JP. Farewell to phenformin for treating diabetes mellitus. Ann Intern Med. 1975;83(4):567-8.

27. Barrantes F, Tian J, Vazquez R, Amoateng-Adjepong Y, Manthous CA. Acute kidney injury criteria predict outcomes of critically ill patients. Crit Care Med. 2008;36(5):1397-403.

28. Vecchio S, Giampreti A, Petrolini VM, Lonati D, Protti A, Papa P, Rognoni C, Valli A, Rocchi L, Rolandi L, et al. Metformin accumulation: lactic acidosis and high plasmatic metformin levels in a retrospective case series of 66 patients on chronic therapy. Clin Toxicol. 2014;52(2):129-35.

29. Renda F, Mura P, Finco G, Ferrazin F, Pani L, Landoni G. Metformin-associated lactic acidosis requiring hospitalization. A national 10 year survey and a systematic literature review. Eur. Rev. Med. Pharmacol. Sci. 2013;17(Suppl 1):45-9.

30. Lalau JD, Race JM. Lactic acidosis in metformin-treated patients. Prognostic value of arterial lactate levels and plasma metformin concentrations. Drug Saf. 1999;20(4):377-84.

31. Seidowsky A, Nseir S, Houdret N, Fourrier F. Metformin-associated lactic acidosis: a prognostic and therapeutic study. Crit Care Med. 2009;37(7):2191-6.

32. Protti A, Russo R, Tagliabue $P$, Vecchio $S$, Singer M, Rudiger A, Foti G, Rossi A, Mistraletti G, Gattinoni L. Oxygen consumption is depressed in patients with lactic acidosis due to biguanide intoxication. Crit Care. 2010;14(1):R22.

33. Robert F, Fendri S, Hary L, Lacroix C, Andrejak M, Lalau JD. Kinetics of plasma and erythrocyte metformin after acute administration in healthy subjects. Diabete Metab. 2003;29(3):279-83.

\section{Submit your next manuscript to BioMed Central and we will help you at every step:}

- We accept pre-submission inquiries

- Our selector tool helps you to find the most relevant journal

- We provide round the clock customer support

- Convenient online submission

- Thorough peer review

- Inclusion in PubMed and all major indexing services

- Maximum visibility for your research

Submit your manuscript at www.biomedcentral.com/submit
C) Biomed Central 